\title{
PREVENTION OF CHILD SEXUAL ABUSE
}

\author{
Nurul Adiningtyas \\ Universitas Mercu Buana Jakarta, Indonesia.
}

\begin{abstract}
Currently, there's an increasing trend in child sexual abuse in Indonesia. Data obtained from Commission for Victim and Witness Protection (LPSK) showed that the number of CSA cases reported in 2018 were doubled from those in 2017. Like many of CSA cases, the perpetrators were someone familiar to the children, and in some cases, it's their close relatives. LPSK stated that only less than $20 \%$ of the perpetrator were strangers. Unfortunately, most CSA cases goes unreported. A study conducted by Wismayantia, et al (2019) shows that lack of knowledge about CSA and insufficient sex education due to the uncomfortable feeling to talk about sexual matters played a significant role in the reluctance to report CSA cases. Moreover, there's a tendency to not report a CSA that were conducted by a family member because most family felt the need to protect the family's name. This program were conducted in North Kembangan Village and aimed to provide an educational overview of the dangers of the effects of CSA. The method provided were introduction and discussion between participants.
\end{abstract}

Keywords: Child Sexual Abuse, Prevention, Education

\section{INTRODUCTION}

According to Commission for Victim and Witness Protection (LPSK), the number of child sexual abuse (CSA) case reported in 2018 were doubled in numbers compared to those in 2017 (LPSK, 2019). Factors such as pornography, social media, lack of sexual education, and sexual deviation (in this case, pedophilia) are main reason why the numbers keeps increasing. Rarely a CSA case were reported by the media with an educational content. They rather keeping it in a bombastic nuance which created, in some cases, curiosities among future perpetrators. However, CSA is still one of a highly under-reported case due to many factors.

Wismayantia, et al. (2019) conducted a study that showed lack of knowledge about CSA as one of several factors that resulted in the reluctance to report CSA cases. Other factors included an uncomfortable feeling to talk about sexual matters, and the fact that the perpetrators were family members played a significant role in the lack of reports.

LPSK (2019) released an information that only under $20 \%$ of the reported case where the perpetrator were total strangers to the victims. That means, over $80 \%$ of the victims knew their abusers, some of them were as close as their own parents, siblings or other close family members such as grandparents, uncles and cousins.

Culture also has a high impact in the under-reporting of CSA. In a society where victims bear the highest burdens in CSA, families tend to keep CSA as a secret for fear of gossip and stigma. Ironically, the same person usually wouldn't hesitate to blame the victim should something similar happened to another family.

North Meruya Administrative Village, where this program were conducted, is located in Kembangan sub-district, West Jakarta Municipality. Problems reported by local activists are social media addiction, drug addiction, trafficking, high rate of school dropouts and child sexual abuse. Some family lives in a day-to-day paycheck and forced both parents to work in order to be able to pay the bills and put food on the table. This, combined with lack of open space for children to play, makes it hard for children to get a sufficient positive stimulation and they tend to roam without supervision, thus increase the chance of CSA for sexual predators.

The purpose of this program is to educate parents and activists about child sexual abuse, how to identify CSA, strategies to prevent them and what to do should CSA already happened. Parents and activists are expected to have basic knowledge on how to deal with CSA after participating in this program.

\section{THEORETICAL REVIEW}

Child sexual abuse (CSA) according to World Health Organization (1999) is any sexual activity which involves a minor, with or without consent, by adult or other minor in a responsible position, that violates the laws or social norms, in order to satisfy the needs of the other person. WHO also classified activities that included in CSA, i.e. forcing a minor to engage in sexual activity, exploiting and trafficking a minor into prostitution and exploiting a minor into pornography.

The psychological impact of CSA is not something to be taken lightly. Depression, guilt, self-blame, eating disorders, somatic concerns, anxiety, dissociative tendencies, repression, denial, sexual problems, relationship problems and trauma has a high correlation with CSA (Sinanan, 2015). Research by Reid (2018) resulted in 
findings that sexual abuse that happened repeatedly during childhood and adolescence could cause in a higher levels in trauma-related shame during adulthood.

When families failed to recognized that the child has become a victim of CSA, the child will be heavily disadvantaged. The victim would not have access to psychological service, or even worse, have to live with their perpetrator as long as they weren't caught. Some of the victim could fall into despair and committed suicide or put themselves into prostitution because of their low self-esteem.

In order to give children an optimum protection by preventing sexual abuse or knowing how to identify and act when CSA occur, by giving knowledge to parents and activists.

\section{IMPLEMENTATION METHOD}

The program conducted in North Kembangan Village consists of several activities: group discussion, and educational session. Before, the participant were given some questions (pre-test) and after the program was done, they were given a post-test to evaluate the program.

Group discussions take place before the material delivery and training events take place. The goal is that the participants get to know each other better and the most important thing is that they can understand the common problem that they have, which is the danger of CSA. Participants then received materials about CSA, and basic counseling skills should they have to deal with CSA victims.

Picture 1. Parents and activists were taught basic communication skill with children

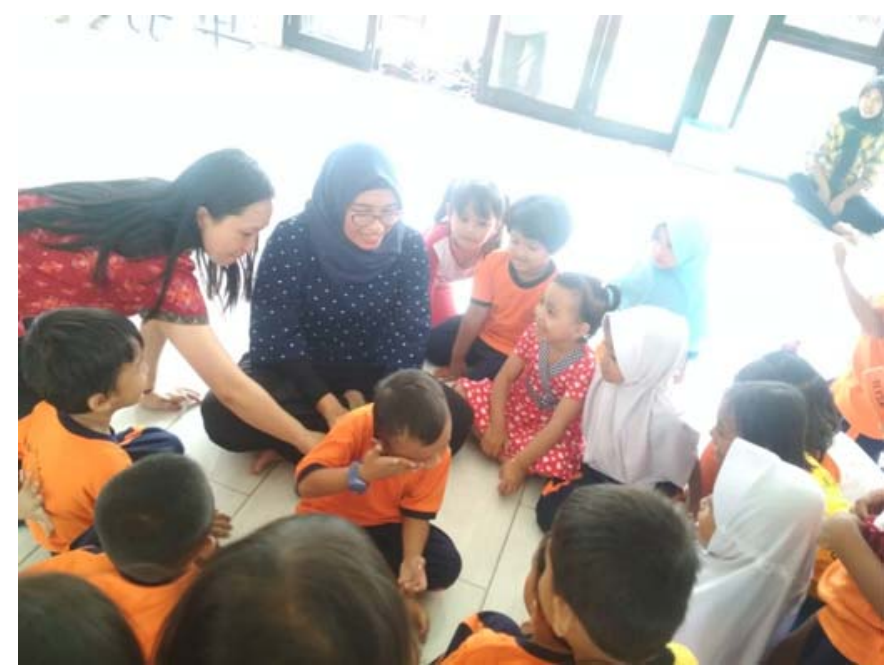

Picture 2. Parents and activists received materials about CSA

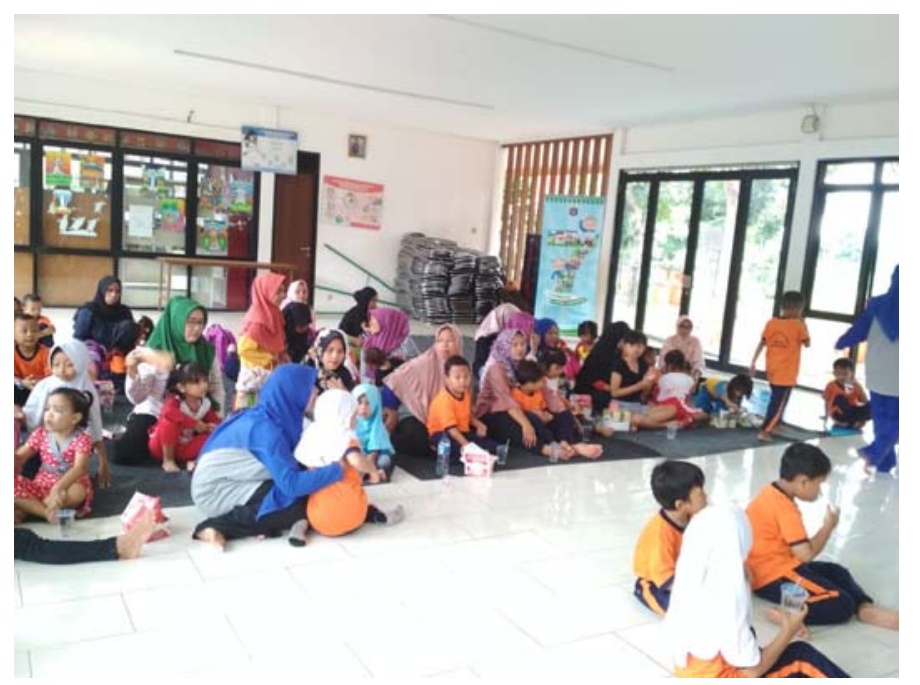




\section{CONCLUSIONS}

From the results of the implementation of community service programs to the communities around the North Kembangan Village it can be concluded as follows;

1. Counseling on the prevention of sexual violence against children is a new thing to be carried out in the North Kembangan Village and participants never receive this program from any party.

2. The program was welcomed enthusiastically by the parents and activists and they were interested in the further process.

\section{BIBLIOGRAPHY}

Lembaga Perlindungan Saksi dan Korban. Lindungi Anak Indonesia dari Kekerasan Seksual di Keluarga. LPSK, Jakarta: 2019. Tersedia di https://www.lpsk.go.id/berita/berita_detail/3030

Reid, Joan A. (2018) "The Imprint of Childhood Abuse on Trauma-Related Shame in Adulthood," Dignity: A Journal on Sexual Exploitation and Violence: Vol. 3: Iss. 1, Article 4. DOI: 10.23860/dignity.2018.03.01.04 Available at:

http://digitalcommons.uri.edu/dignity/vol3/iss1/4http://digitalcommons.uri.edu/dignity/vol3/iss1/4

Sinanan, Allison. (2015). Trauma and Treatment of Child Sexual Abuse. Journal of Trauma \& Treatment. s4. 10.4172/2167-1222.S4-024.

World Health Organization. Report of the consultation on child abuse prevention (WHO/HSC/PVI/99.1) World Health Organization; Geneva (Switzerland): 1999. Available at:http://www.who.int/mip2001/files/2017/childabuse.pdf.

Wismayantia, et al. (2019). 'Child sexual abuse in Indonesia: A systematic review of literature, law and policy' Elsevier, vol. 95, September 2019, 104034 